\title{
INFRAESTRUTURAS DE C\&T NO BRASIL E PADRÕES DE ESPECIALIZAÇÃO COM BASE NO CONHECIMENTO
}

\author{
Camila Maria de Andrade Tolentino (Cedeplar-UFMG) \\ Márcia Siqueira Rapini (Cedeplar-UFMG)
}

\section{RESUMO}

O artigo analisa a geração de conhecimento e o processo de aprendizado nas infraestruturas de C\&T vinculadas ao MCTI à partir de dados levantados pelo próprio Ministério em parceria com o CNPq. Partindo-se de uma caracterização das infraestruturas em relação às áreas do conhecimento, o tipo de atividade realizada (pesquisa, ensino, serviço tecnológico, extensão e desenvolvimento tecnológico), a interação com agentes externos e de uma análise de cluster foi possível caracterizar as estruturas em 3 agrupamentos. Os agrupamentos sinalizaram para diferentes padrões de geração de conhecimento e de aprendizado no interior das infraestruturas.

PALAVRAS-CHAVE: infraestruturas de C\&T; processos de aprendizado; Brasil.

\begin{abstract}
The article analyzes the generation of knowledge and the learning process in S\&T infrastructures linked to the MCTI from data collected by the Ministry in partnership with CNPq. Starting from a characterization of infrastructure in relation to scientific areas, the type of activity carried out (research, teaching, technical service, extension and technological development), interaction with external agents and a cluster analysis was possible to characterize the structures in 3 groups. The clusters show different patterns of knowledge generation and learning.
\end{abstract}

KEY-WORDS: S\&T infrastructures, learning process, Brazil

JEL: 039 


\section{INTRODUÇÃO}

No Brasil o processo de industrialização e construção de capacidades nacionais contou desde o início com o fomento à criação e ao desenvolvimento de uma infraestrutura de C\&T. Na Era da Economia do Conhecimento - que tem o conhecimento como o principal produto e o aprendizado como o principal processo - essas infraestruturas têm o potencial de contribuir para o processo de inovação realizado pelas empresas. Contudo, tem-se verificado que a formação e consolidação da base de pesquisa não é acompanhada, na mesma medida, por um esforço por parte das empresas.

No contexto das infraestruturas de C\&T o conjunto de atividades desempenhado por elas depende do conhecimento prévio acumulado, ao mesmo tempo em que envolve um processo contínuo de aprendizado que permite a expansão da sua base. Assim, dependendo do tipo de conhecimento presente nessas infraestruturas elas se tornam mais aptas para realizar certos tipos de atividades e contribuir em diferentes frentes no processo de inovação, as quais muitas vezes não contam com os esforços das firmas. Sendo assim, é importante discutir as formas que os processos de aprendizado podem assumir no desenvolvimento de competências.

De forma a captar as variantes dos processos de aprendizado recorreu-se à tipologia de Lundvall e Johnson (1994) que propõe uma distinção entre dois tipos de processos de aprendizado: o "learning by searching" e o "learning by producing". Enquanto o primeiro estaria relacionado principalmente aos conhecimentos do tipo know-what, know-why, o segundo estaria ligado principalmente ao know-who e know-how. Ainda que com dinâmicas distintas, todas as categorias de conhecimento têm grande relevância econômica e estariam combinadas no processo de inovação.

Tal distinção entre os dois tipos de aprendizado é levada adiante por Jensen et al (2007). Por um lado, tem-se um modo de aprendizado baseado na produção e uso de conhecimento codificado e técnico, denominado Science, Technology and Innovation mode (STI). Por outro lado, tem-se o modo baseado na experiência, denominado de Doing, Using and Interacting mode (DUI). Enquanto o primeiro abrange notadamente know-what e knowwhy, o segundo tipo envolve principalmente know-who e know-how. A geração de inovações, por sua vez, dependeria da capacidade de conciliar ambos os modos de aprendizado, seja dentro das infraestruturas de C\&T ou das firmas. Entretanto, considerando a formação do sistema nacional de inovação brasileiro podemos notar um maior esforço no desenvolvimento de competências dentro das infraestruturas de C\&T e não dentro das empresas.

A partir dessas tipologias, buscou-se qualificar o tipo de conhecimento e os processos de aprendizado que têm lugar nas infraestruturas de C\&T e em qual tipo de processo elas teriam mais a contribuir. Como ponto de partida, tem-se que são concebidas, sobretudo com o propósito de dar lugar a processos da forma STI. Entretanto, no escopo das suas atividades sugerimos que elas possam também desenvolver processos de aprendizado do tipo DUI.

Este trabalho utiliza informações reunidas pelo esforço desenvolvido pelo IPEA, MCTI/Finep e CNPq, cujos resultados foram apresentados por De Negri e Squeff (2016). Os dados levantados constituem o Diretório de Infraestruturas de Pesquisa (DIP), cujo propósito é permitir um diagnóstico consistente a respeito da infraestrutura pública de C\&T no Brasil. A amostra é constituída por instalações localizadas em instituições públicas de pesquisa vinculadas ao MCTI em todo o território nacional. Os coordenadores dessas instalações foram os responsáveis por declarar as informações com base em um questionário que abrange questões a respeito das suas instalações físicas, atividades realizadas, fontes de renda, pesquisadores e pessoal de apoio.

Estas informações foram utilizadas para analisar o tipo de conhecimento gerado nas infraestruturas de C\&T no Brasil. Para tal fim, ademais de se caracterizar estas estruturas de 
forma geral, foi também realizada uma análise de cluster na busca de categorizar as infraestruturas de pesquisa. Ademais desta introdução o trabalho possui mais quatro seções. A segunda apresenta de forma resumida o desenvolvimento da infraestrutura de C\&T no Brasil, desde sua origem até o período mais recente. A terceira seção discute o processo de aprendizado e a geração de conhecimento para o processo de inovação, contemplando as infraestruturas de C\&T. A quarta seção caracteriza as infraestruturas em termos de idade, modernização, área do conhecimento e colaboração, apresentando o resultado da aplicação da técnica multivariada de cluster. A quinta seção conclui o trabalho.

\section{DESENVOLVIMENTO DA INFRAESTRUTURA DE C\&T NO BRASIL}

O Brasil diferentemente das demais colônias da França, Inglaterra e Holanda, não obteve de Portugal a transferência de alguma forma de ciência, visto o pouco desenvolvimento da mesma na metrópole. O colonialismo, predatório e explorador, não tinha maiores pretensões da criação de um ambiente propício para o desenvolvimento e formação de uma sociedade e de instituições voltadas à disseminação e à produção do conhecimento.

Até a mudança da corte para o Rio de Janeiro no século XIX as iniciativas de estabelecimentos de instituições de pesquisa eram esporádicas e na maioria das vezes pouco expressivas em termos de atuação. Já no início do referido século várias instituições foram criadas no Rio de Janeiro (como Biblioteca Nacional, Jardim Botânico, entre outras) tendo participação ativa do imperador nos assuntos de ciência, tecnologia e educação. Mas eram ausentes setores sociais que vislumbrassem a atividade científica como importante e consequentemente passível de investimentos nacionais (Schwartzman, 1979, p.52).

$\mathrm{Na}$ primeira República foram criados instituições e centros de pesquisas como Instituto Agronômico de Campinas (IAC), Instituto Butantã e Instituto de Manguinhos, visando atender às necessidades emergenciais do país como a exploração de recursos naturais, a expansão da agricultura e o saneamento dos principais portos e cidades. O crescimento da indústria, o desenvolvimento propiciado pela construção das ferrovias e o aumento da colheita demandavam soluções imediatas aos obstáculos que surgiam (Schwartzman, 1991). Observase, nestes casos, portanto, que condições particulares levavam ao desenvolvimento de capacitações científicas específicas ${ }^{1}$.

A Escola de Minas de Ouro Preto foi a primeira instituição a introduzir cursos de treinamento voltado à construção e expansão da rede ferroviária. Posteriormente a Escola Politécnica de São Paulo estabeleceu o Laboratório de Resistência Material (LEM) que era utilizado para testar materiais e equipamentos para as ferrovias e para o setor de energia elétrica (Schwartzman, 1991). Em 1932 a autonomia do LEM é ampliada e em 1934 é transformado no Instituto de Pesquisa Tecnológica (IPT) sendo autônomo à Escola Politécnica. A criação do Instituto foi seguida ainda de uma ampliação das áreas de atuação para atender tecnicamente a indústria. A criação do Instituto Nacional de Tecnologia (INT) remonta ao mesmo período, em substituição à Estação Experimental de Combustíveis e Minérios. A Estação, criada em 1921 no Rio de Janeiro, objetivava a realização de pesquisas tecnológicas no setor energético, tanto de combustíveis como de recursos minerais. O INT durante um período foi o principal centro de pesquisas tecnológicas no país, excluindo-se as ciências biomédicas.

Até este período o sistema educacional caracterizava-se pela existência de Escolas de Ensino Superior em áreas tradicionais, como direito, medicina e engenharias. A resistência à criação de universidades por parte do governo e parlamento (durante período monárquico)

\footnotetext{
${ }^{1}$ Lopes (1979) ressalta que estes domínios estavam diretamente relacionados aos interesses de grupos dominantes.
} 
não permitiu o estabelecimento de tais instituições. A ‘Reforma Francisco Campos’ de 1931 foi o primeiro esforço nesta direção, tendo como concepção a criação de uma universidade nacional em um sistema centralizado (Schwartzman, 1991). O seu ápice no contexto de um regime militar centralizador, não permitiu a consolidação do sistema universitário baseado em comunidade acadêmica autônoma, assim como a incorporação da pesquisa científica no ambiente universitário.

As primeiras universidades brasileiras foram criadas a partir de iniciativas dos estados de São Paulo e Rio de Janeiro e não do governo federal. De acordo com o decreto estadual 6.283 os objetivos da Universidade de São Paulo (USP) estabelecida em 1934 seriam: "promover o progresso da ciência através da pesquisa; (...) transmitir o conhecimento; (...) formar especialistas e profissionais; e (...) promover a difusão e popularização das ciências, artes e letras por meio de cursos de curta duração, conferências, programas de rádio, etc” (Schwartzman, 1991, capítulo 4, p.25). A autonomia administrativa da universidade e os recursos disponíveis no estado levaram a excelência da Faculdade de Filosofia, Ciências e Letras tornando-se a instituição científica mais importante do país depois do Instituto Oswaldo Cruz.

No primeiro governo Vargas, a industrialização brasileira ainda incipiente não demandava pesquisa tecnológica e científica. As exceções eram algumas áreas dinâmicas da agricultura com articulação com interesses econômicos e área de biomédica com demandas crescentes à melhoria da qualidade na medicina. Até o presente momento a ciência ainda não havia adquirido autonomia suficiente e as atividades de pesquisa científica eram iniciativas isoladas, em grande parte introduzidas por emigrantes estrangeiros que vieram a trabalhar nas instituições de pesquisas.

Durante a Segunda Guerra, a construção da bomba atômica, vinculada a progressos na ciência e tecnologia, vislumbrava o papel positivo que as mesmas poderiam desempenhar no desenvolvimento dos países latino americanos. Um primeiro esforço de mobilização da comunidade acadêmica para o diálogo com outras associações do país consistiu na criação da Sociedade Brasileira Para o Progresso da Ciência (SBPC) em 1948. De acordo com Fernandes (1990) (em Velho, 1996) além de ser o inicio da institucionalização da ciência no país foi o reconhecimento do papel da mesma no progresso nacional.

Posteriormente foi criado o Conselho Nacional de Pesquisas (CNPq) em 1951 para apoiar o desenvolvimento da ciência em várias áreas do conhecimento, sendo uma das mais importantes iniciativas governamentais no estabelecimento de política nacional de C\&T (Velho, 1996). Ao final do mesmo ano foi criada a Comissão de Acompanhamento de Pessoal de Ensino Superior (CAPES) para o financiamento e estímulo à qualificação de recursos humanos nas universidades e instituições de P\&D fortalecendo as capacidades científicas e tecnológicas nacionais. Somente com este último seria possível uma inserção favorável no capitalismo internacional via a industrialização já em andamento (Velho, 1996).

A percepção da energia nuclear como estratégica para fins militares levou à criação do Centro Brasileiro de Pesquisas Físicas (CBPF), objetivando a introdução da pesquisa atômica no país. Posteriormente, o Instituto de Pesquisas Radioativas de Minas Gerais foi organizado em 1953 e no ano seguinte a Universidade do Rio de Janeiro criou o primeiro curso de Engenharia Nuclear. A necessidade de dar uma maior autonomia a esta importante fonte de tecnologia levou a um redirecionamento do programa de energia atômica e a criação de uma nova instituição em 1951, a Comissão Nacional de Energia Nuclear (CNEN) (Dahlman; Frischtak, 1993). ${ }^{1}$ Outra significativa iniciativa militar no período constituiu na criação do Centro Técnico da Aeronáutica (CTA) em 1947 e do estabelecimento do Instituto Tecnológico da Aeronáutica (ITA) em 1950.

O período posterior de 1964 a 1985 particulariza-se por diversas mudanças estruturais na economia brasileira. No âmbito da infraestrutura de C\&T, tem-se a "formalização da 
infraestrutura em ciência e tecnologia e de esforços de definição de políticas científicas e tecnológicas e de construção de instituições” (Dahlman; Frischtak, 1993, p.419). O processo de industrialização via substituição de importações levou a completa transformação da base produtiva nacional, completando o ciclo da industrialização pesada e de bens de capital. As políticas adotadas permitiram um salto substancial na qualidade da ciência nacional não tendo, contudo, contrapartida no desenvolvimento de tecnologia local.

No período do II PND o desenvolvimento científico e tecnológico tornou-se objetivo específico de política a nível federal, tendo-se o maior empenho na construção de uma capacitação científica nacional e os recursos destinados às mesmas foram aumentados, via a criação de instituições de financiamento como a FUNTEC, FINAME e FINEP. Pela primeira vez foi introduzido um sistema de planejamento para as atividades de C\&T sendo criado o Sistema Nacional de Desenvolvimento Científico e Tecnológico (SNDCT) em 1975 e o Fundo Nacional de Desenvolvimento Científico e Tecnológico (FNDCT) para financiá-lo ${ }^{2}$.

Na década de 70 outros esforços foram realizados almejando o desenvolvimento tecnológico nacional. Pelo lado da indústria, criou-se a Secretária de Tecnologia Industrial (STI) em 1972 abrangendo várias das Instituições de C\&T subordinadas ao Ministério da Indústria e Comércio. Dentre as atribuições da STI destaca-se a realização de atividades de P\&D nas suas instituições e financiamento para o desenvolvimento tecnológico em empresas privadas e estatais (Dahlman; Frischtak, 1993). No ano seguinte foi criada a EMBRAPA, em substituição ao Departamento Nacional de Pesquisa e Experimentação Agropecuária (DNPEA) uma vez constatada que a simples transferência de tecnologia estrangeira não solucionava os problemas do país. Era necessário realizar pesquisas independentes (Cabral, $1994)^{3}$. Neste período maiores recursos foram destinados às infraestrutura de C\&T. O dispêndio em C\&T/PIB que era 0,24\% em 1970 passou para 0,58 em 1980. Contudo,

Nos anos 80 a crise financeira mundial repercutiu no Brasil com estagnação econômica e fortes pressões inflacionárias. Neste cenário a Política Industrial implementada limitou-se a uma atuação passiva, visando a manutenção do parque industrial diversificado, que não acompanhou as alterações nos padrões internacionais de competitividade (Cassiolato et al., 1996). No âmbito da infraestrutura de C\&T, a meta era estimular a capacidade tecnológica das firmas nacionais com o fortalecimento da infraestrutura. Ao nível institucional teve-se a criação do Ministério de Ciência e Tecnologia (MCT) em 1985 abrangendo o CNPq, a FINEP e a SEI ${ }^{4}$. O principal objetivo era administrar o aumento de recursos orçamentários destinados à Finep e ao CNPq, visto que os mesmos, neste ano, foram equivalentes a $40 \%$ dos auferidos em 1979. Esta meta foi mantida por pequeno período de tempo, sendo que os para Finep reduziram ao final de 1987. Os destinados ao CNPq mantiveram-se até os anos 90 em decorrência principalmente das políticas específicas voltadas ao desenvolvimento científico e ao fornecimento de bolsas de estudo.

Entre 1996-2002 novas modalidades e mecanismos de financiamento estavam sendo gestados. Em 1997 surgiu o primeiro fundo vinculado a parcelas de royalties do petróleo para captar recursos para a área de C\&T: CT Petro-Fundo Setorial do Petróleo. O CT-Petro foi regulamentado em 1998 entrando em operação em 1999. O Fundo Setorial de Telecomunicações - FUNTTEL foi criado em 2000 sendo suas receitas oriundas de uma

\footnotetext{
2 A partir do SNDCT foram criados três Planos Básicos entre 1973 e 1985. O I PBDCT entre 1973-74, o II PBDCT entre 1975-79 e o III PBDCT entre 1980-85.

${ }^{3}$ De acordo com Cabral (1994) os militares percebiam que a agricultura era uma barreira ao desenvolvimento e visto a exclusão da opção de reforma agrária, a alternativa mais viável era a modernização através da mudança tecnológica.

${ }^{4}$ De acordo Velho (1996) o fato do MCT entre 1985 e 1990 ser transformado em Secretária do Ministério da Indústria e Comércio, passando novamente a MCT e posteriormente transformado em Secretária de Ciência e Tecnologia, refletiu a falta de clareza do Estado por parte de uma política de C\&T(p.51)
} 
contribuição (de 0,5\%) sobre a receita bruta das empresas prestadoras de serviços de telecomunicação e sobre a arrecadação bruta (de 1\%) de eventos participativos realizado por meio de ligações telefônicas (Pacheco, 2007).

Em 2001, foram implantados mais 5 (cinco) fundos: como o de Informática (20/4/2001), o de Recursos Minerais (16/7/2001), o de Energia Elétrica (16/7/2001), o de Recursos Hídricos (19/7/2001) e o Espacial (12/9/2001). Estes fundos foram concebidos em uma perspectiva setorial, sendo os recursos oriundos do setor no qual deveriam ser aplicados. Os Fundos de Infraestrutura (26/4/2001) e Verde-amarelo (11/4/2002), por sua vez, foram constituídos visando uma atuação mais sistêmica abrangendo os diversos setores, sem a necessidade de vincular a receita e a aplicação a um mesmo setor (Pereira, 2005). O Fundo Verde-amarelo (FVA) visava incentivar a interação entre universidades e empresas no desenvolvimento científico e tecnológico brasileiro. Em 2002 foram constituídos mais um conjunto de fundos setoriais que contemplavam áreas de interesse nacional, sendo: Biotecnologia, Agronegócios, Aeronáutica, Transportes, Saúde e da Amazônia. Com exceção do FUNTTEL os recursos dos demais fundos são alocados no FNDCT e administrados pela FINEP.

A criação dos Fundos Setoriais imprimiu uma nova dinâmica, uma reorientação da política de C\&T, que passa a ser direcionada à inovação e aos esforços realizados pelas empresas. "Rompeu-se, assim, com toda a trajetória recente de apoio à pesquisa que, quando muito, privilegiava a evolução da ciência básica e acadêmica e, principalmente, a instalação de uma ampla infraestrutura de pesquisa, de difícil manutenção ao longo do tempo” (Bastos, 2012, p.129).

\section{APRENDIZADO E GERAÇÃO DE CONHECIMENTO}

Diferentes tipos de conhecimento têm dinâmicas distintas e podem ser incorporados pelos indivíduos por diferentes canais. Enquanto o conhecimento científico pode ser adquirido através de livros, pesquisa e acesso a bases de dados, conhecimentos práticos dependem da execução de determinadas atividades e da vivência direta no cotidiano das organizações. Para entendermos essa variabilidade é interessante resgatar a tipologia proposta por Lundvall e Johnson (1994), a qual sugere a distinção entre quatro tipos de conhecimento: know-what, know-why, know-who e know-how. Ainda que com dinâmicas distintas, todas essas categorias de conhecimento teriam grande relevância econômica e estariam combinadas no processo de inovação.

O primeiro tipo de conhecimento - know-what - se refere ao conhecimento sobre fatos, mais próximo daquilo que é entendido aqui como informação. Já o segundo - know-why - remete aos princípios e leis de movimento da natureza, muito importante para o desenvolvimento tecnológico enquanto forma de reduzir possíveis erros e falhas. Ambos os tipos de conhecimento apresentam características comuns, notadamente no que se refere à alta apropriabilidade, podendo ser descritos e reproduzidos por outros sem custos altos. Por sua vez, o terceiro tipo - know-who - se refere a um processo interativo que envolve o conhecimento sobre "quem sabe fazer o que". Por fim, know-how se refere às habilidades de se fazer algo na prática. Estes últimos, ao contrário dos dois primeiros, dificilmente podem ser codificados e reproduzidos por outros agentes. Particularmente, o know-how encontra-se no centro do processo econômico, uma vez que é mais difícil aprender como fazer e produzir mudanças do que conhecer sobre fatos e ciência (Lundvall; Johnson, 1994).

A aquisição dos quatro tipos de conhecimento, por sua vez, depende em grande medida da interação entre os agentes, ainda que esta seja mais significativa em casos específicos. Além disso, ela não necessariamente deriva de atividades focadas na produção de conhecimento, mas em atividades econômicas das mais diversas. Nesse sentido, Lundvall e Johnson (1994) propõem uma distinção entre dois tipos de processos de aprendizado: aquele 
que é intencional, denominado de "learning by searching" e aquele que é um subproduto das atividades econômicas, chamado de "learning by producing". Enquanto o primeiro envolve atividades de treinamento, $\mathrm{P} \& \mathrm{D}$ e educação, o segundo abrange processos de learning by doing, learning by using e learning by interacting. Esses não se tratam, porém de atividades excludentes, mas, ao contrário, interdependentes.

A distinção entre ambos os tipos de aprendizado é levada adiante por Jensen et al (2007). Por um lado, tem-se um modo de aprendizado baseado na produção e uso de conhecimento codificado e conhecimento técnico, o qual é denominado de Science, Technology and Innovation mode (STI). Por outro lado, tem-se o modo baseado na experiência, denominado de Doing, Using and Interacting mode (DUI). Enquanto o primeiro abrange notadamente know-what e know-why, o segundo tipo envolve principalmente knowwho e know-how. Ao contrário da tendência de se associar a produção de inovações ao primeiro modelo, os autores mostram que as empresas mais inovativas foram aquelas capazes de conciliar ambos os modos de aprendizado, rompendo com a pressuposta dicotomia entre eles.

Nesse contexto, as universidades e instituições de pesquisa fizeram-se relevantes no desenvolvimento dos processos de aprendizado do tipo STI, enquanto atividades focadas na produção de conhecimento científico na forma de learning by searching e detentoras do conhecimento da forma know-what e know-why. Entretanto, como argumentamos anteriormente, o conhecimento é resultado de um processo iterativo e pode ser derivado também de atividades secundárias das instituições. Sendo assim, tais instituições poderiam desenvolver também conhecimentos do tipo know-who e know-why, contidos principalmente dentro das empresas.

\section{CARACTERIZAÇÃO GERAL DA INFRAESTRUTURA DE PESQUISA}

Conforme os dados do DIP, a maior parte das infraestruturas públicas de C\&T no Brasil está localizada na região Sudeste do país, sobretudo nos estados de São Paulo, onde se encontra 24\% do total de infraestruturas, seguido pelo Rio de Janeiro (19\%) e Minas Gerais (13\%). Além disso, parte considerável delas está concentrada também na região Sul, distribuindo-se entre os estados do Rio Grande do Sul (10\%), Paraná (7\%) e Santa Catarina (7\%). Além disso, é interessante notar que 68\% das infraestruturas do país estão localizadas em regiões metropolitanas, isto é, a centralidade é um aspecto notável quanto a sua distribuição espacial.

Tabela 1: Distribuição das infraestruturas por região

\begin{tabular}{lcc}
\hline Região & Número de infraestruturas de C\&T & Em região metropolitana \\
\hline Centro-Oeste & 113 & 11 \\
Nordeste & 170 & 139 \\
Norte & 54 & 47 \\
Sudeste & 1004 & 723 \\
Sul & 419 & 270 \\
\hline \hline
\end{tabular}

Fonte: IPEA, MCTI/Finep e CNPq.

A maior parte delas (57\%) é relativamente recente, tendo sido fundada depois dos anos 2000, o que estaria em grande medida relacionado aos ciclos de investimentos e aportes financeiros realizados desde então. Dentre eles destaca-se o Fundo de Infraestrutura CTINFRA, instituído em 2001 com o objetivo de fortalecer a infraestrutura de pesquisa das instituições públicas brasileiras (De Negri; Squeff, 2016). Além disso, 71\% das infraestruturas 
alegam ter passado por investimentos significativos ${ }^{5}$ de modernização nos últimos cinco anos. Por sua vez, sendo o aprendizado um processo cumulativo, pode-se supor que as infraestruturas mais antigas tenham mais conhecimento acumulado e sejam mais consolidadas nos seus respectivos campos.

Quanto à área do conhecimento dessas infraestruturas, predominam as Engenharias e as Ciências Exatas e da Terra, tanto em número de infraestruturas quanto de pesquisadores ${ }^{6}$. O questionário permitia ainda que os respondentes assinalassem mais de uma grande área e, nestes casos, as infraestruturas foram classificadas como multidisciplinares. Vale ainda notar que mesmo dentre estas, 53\% têm Engenharias e 56\% têm Ciências Exatas e da Terra como uma das áreas declaradas. Além disso, as multidisciplinares têm a maior média de pesquisadores por infraestruturas (aproximadamente 6). Aquelas da área de Saúde têm, em média, aproximadamente 5 pesquisadores, enquanto as demais áreas mobilizam, em média, aproximadamente 4 pesquisadores.

\section{Tabela 2: Grande área de conhecimento por número de infraestruturas de C\&T e pesquisadores}

\begin{tabular}{lcc}
\hline Grande área & $\begin{array}{c}\text { Número de } \\
\text { infraestruturas de C\&T }\end{array}$ & $\begin{array}{c}\text { Número de } \\
\text { pesquisadores }\end{array}$ \\
\hline Ciências Agrárias & 202 & 746 \\
Ciências Biológicas & 318 & 1254 \\
Ciências da Saúde & 66 & 343 \\
Ciências Exatas e da & 368 & 1652 \\
Terra & 491 & 2175 \\
Engenharias & 315 & 1888 \\
Multidisciplinar &
\end{tabular}

Fonte: IPEA, MCTI/Finep e CNPq.

As áreas do conhecimento, por sua vez, variam em termos das suas demandas específicas por determinados tipos de conhecimento. Isso nos faria supor, por exemplo, que áreas mais aplicadas como Saúde e Engenharia possivelmente se aproximariam mais de processos do tipo DUI do que as ciências puras (hard sciences) como as Ciências Biológicas ou as Ciências Exatas e da Terra, por exemplo, as quais estariam voltadas mais especificamente para o modo STI. Além disso, certas áreas podem ainda ser mais intensivas em capital (utilização de equipamentos) do que outras, de modo que possuem diferentes requisitos para a avaliação das suas infraestruturas.

No que se refere à intensidade de uso das instalações contempladas no DIP, predomina a realização de pesquisa, uma vez que $81 \%$ das infraestruturas declaram realiza-la continuamente, seguida pelo ensino (39\%), confirmando que, de modo geral, as infraestruturas são mais bem enquadradas como instituições voltadas para STI. Por sua vez, 35\% delas declaram estar continuamente dedicadas ao desenvolvimento de tecnologias. Já as atividades de extensão tecnológica e prestação de serviços tecnológicos, quando realizados, de modo geral, são esporádicas. Nesse sentido, pode-se supor que a capacidade de realizar tais atividades dependeria em grande medida de conhecimentos derivados de processos do tipo DUI, os quais poderiam ser adquiridos como um subproduto das suas atividades principais.

\footnotetext{
${ }^{5}$ Investimentos significativos foram definidos como aqueles que correspondessem a pelo menos $10 \%$ do valor estimado da infraestrutura de C\&T (De Negri; Squeff, 2016).

${ }^{6}$ Isso estaria em grande medida relacionado ao fato de que as infraestruturas de C\&T em questão são vinculadas especificamente ao MCTI, enquanto infraestruturas de outras áreas estariam vinculadas a outros ministérios correlatos, como pode ser o caso da área de saúde, por exemplo.
} 
Figura 1: Intensidade de uso das infraestruturas de C\&T por atividade

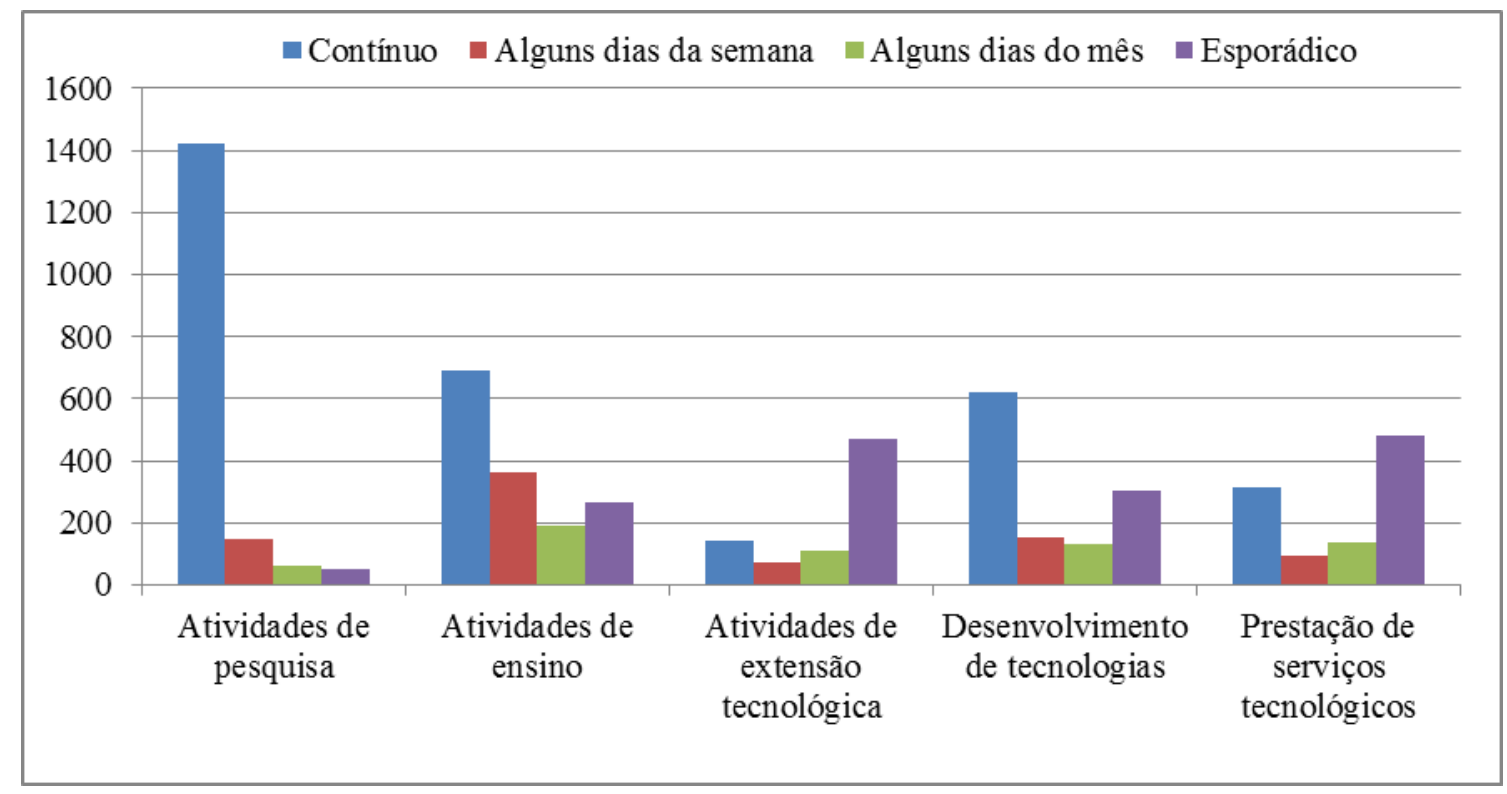

Fonte: IPEA, MCTI/Finep e CNPq.

Considerando que a aquisição de conhecimento pela execução de uma atividade pode ajudar a desenvolver competências para a diversificação do escopo das suas ocupações, cabe avaliar a diversificação das tarefas nas infraestruturas. Dentre aquelas que se dedicam continuamente à pesquisa, principal atividade das infraestruturas, 44\% também dão lugar continuamente às atividades de ensino, $42 \%$ ao desenvolvimento de tecnologias, $10 \%$ a extensão tecnológica e $18 \%$ a prestação de serviços tecnológicos. Por sua vez, dentre as infraestruturas que prestam tais serviços de forma contínua, $80 \%$ delas também estão dedicadas à pesquisa, 54\% ao desenvolvimento de tecnologias, $28 \%$ à extensão tecnológica e $43 \%$ aos serviços.

Além disso, como foi discutido, o processo de aprendizado é interativo e cresce através da relação com outros agentes e instituições, sobretudo por meio da transmissão de conhecimento tácito. Sobre a interação das infraestruturas com demais agentes do NSI, tem-se que a maior parte delas (89\%) declarou ter estabelecido algum tipo de cooperação, seja com outras instituições de pesquisa, empresas ou agências de fomento, nacionais ou estrangeiras. No entanto, é possível observar que as infraestruturas valorizam pouco a interação com estes últimos. Para elas é mais importante a cooperação com outras instituições de pesquisa e agências de fomento nacionais. Isso aponta na direção contrária à internacionalização dessas infraestruturas bem como de uma possível aproximação com o setor produtivo, conforme sugerido por De Negri e Squeff (2016). Assim sendo, embora quase a totalidade delas tenha estabelecido algum tipo de cooperação, sua articulação com os demais agentes é ainda incipiente. 
Figura 2: Grau de importância atribuído à interação com agentes externos

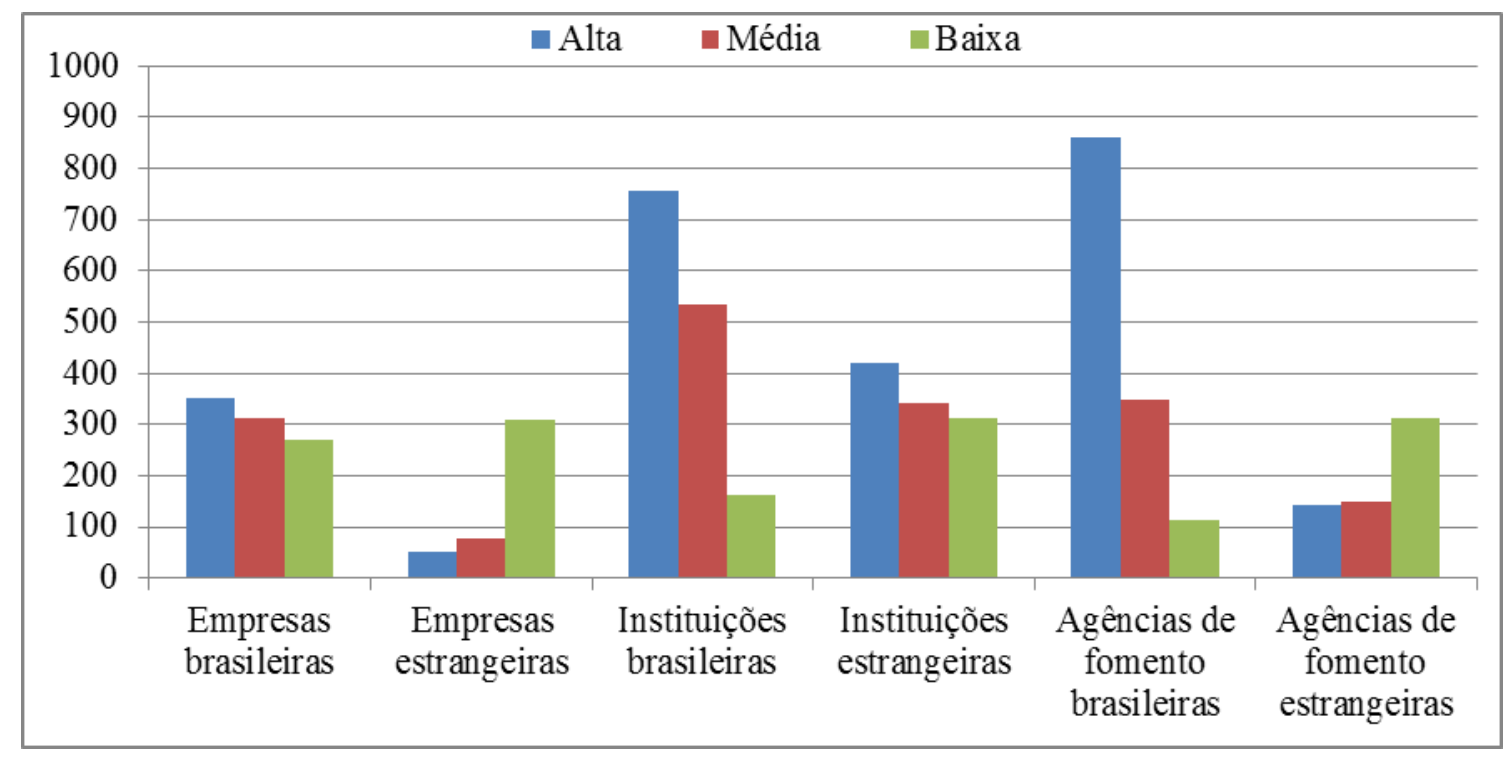

Fonte: IPEA, MCTI/Finep e CNPq.

De modo a captar a articulação das infraestruturas dedicadas, sobretudo aos modos de aprendizado via STI, pode-se explorar a sua relação setor produtivo, onde prevaleceriam os processos do tipo DUI, a partir da variável de prestação de serviços tecnológicos para empresas. Isso nos levaria a supor que como um subproduto dessa atividade, as infraestruturas seriam capazes de absorver alguma parcela de conhecimento típica desses processos de aprendizado. No escopo do levantamento do DIP, tal atividade foi definida como "a prestação de serviço tecnológico, de pesquisa ou de apoio à inovação por meio de instrumento formal (acordo/convênio) e/ou mediante remuneração” (De Negri; Squeff, 2016, p.35). Tem-se que $69 \%$ das infraestruturas prestaram algum tipo de serviço tecnológico, das quais 62\% atenderam empresas. Entretanto, dentro do universo da amostra esse valor corresponde a apenas 43\% do total das infraestruturas de C\&T. Do total de serviços prestados, no entanto, os principais clientes não foram empresas, mas outros pesquisadores, sobretudo para a realização de ensaios e testes. Já os serviços mais demandados pelas empresas foram os de consultoria e assessoria técnico-científicas. Estes foram também os mais demandados pelo governo, embora este tenha sido o cliente menos expressivo das infraestruturas.

Tabela 3: Serviços prestados pelas infraestruturas de C\&T

\begin{tabular}{lccc}
\hline Tipo de serviço & Empresas & Governo & Pesquisadores \\
\hline Consultoria e assessoria técnico-científicas & 402 & 227 & 338 \\
Ensaios e testes & 364 & 149 & 427 \\
Desenvolvimento e aperfeiçoamento de processos & 244 & 89 & 228 \\
Desenvolvimento e aperfeiçoamento de produtos & 236 & 66 & 162 \\
Análise de materiais & 230 & 88 & 343 \\
Análise de propriedades físico-químicas & 177 & 67 & 232 \\
Elaboração e testes de protótipos & 160 & 52 & 130 \\
Informação tecnológica & 144 & 71 & 149 \\
Exames laboratoriais & 113 & 74 & 177
\end{tabular}


(continuação)

\begin{tabular}{lccc}
\hline Tipo de serviço & Empresas & Governo & Pesquisadores \\
\hline Serviços ambientais & 93 & 60 & 95 \\
Calibração & 65 & 33 & 70 \\
Metrologia & 50 & 37 & 51 \\
Certificação & 47 & 12 & 23 \\
Inspeção & 45 & 24 & 28 \\
Scale up (escalonamento) & 30 & 4 & 13 \\
Manutenção de equipamentos científicos & 20 & 8 & 51 \\
Acesso a banco de células, microrganismos etc. & 12 & 8 & 71 \\
Outros & 46 & 37 & 56 \\
\hline \hline
\end{tabular}

Fonte: IPEA, MCTI/Finep e CNPq.

Além disso, no escopo do DIP, os coordenadores foram solicitados a declarar em quais os setores de atividades as linhas de pesquisa da sua infraestrutura de C\&T poderiam ser aplicadas, com base na CNAE (era possível apontar mais de um setor). Como foi observado por De Negri e Squeff (2016), há indícios de que os respondentes não associam as atividades da infraestrutura de C\&T às atividades estritamente econômicas, dado que a maior parte delas declaram aplicações na seção de "atividades profissionais, científicas e técnicas”, das quais 548 se referiram à divisão de pesquisa e desenvolvimento científico.

\subsection{Categorização das infraestruturas de $C \& T$ evidências dos agrupamentos}

De modo a categorizar as infraestruturas de pesquisa foi utilizada a técnica multivariada de análise de clusters com o objetivo de agrupar infraestruturas de C\&T semelhantes, com base nas características observadas a partir do DIP. Uma vez agrupadas, pretende-se extrair das características de cada categoria quais os tipos de conhecimento e processos de aprendizado que cada uma delas seria capaz de desenvolver.

Para tanto, foi utilizado o método não-hierárquico kmedians, uma variação do método k-means. A partir dele, o centróide de cada grupo é computado a partir da mediana e não da sua média, o que o faz menos sensível a valores extremos. Trata-se de um método iterativo que se inicia a partir da definição de um critério inicial de partição para a formação de $k$ grupos. Formados os grupos, são então calculadas suas respectivas medianas e as observações são alocadas entre eles de modo a minimizar sua distância até o centróide ${ }^{7}$. O processo é repetido até que todas as observações sejam alocadas em um dos $k$ grupos.

Para os casos em que variáveis de diferentes tipos são incluídas na análise cluster - no caso incluem-se variáveis ordinais, intervalares e porcentagens -, Kaufman e Rouseeuw (1990) sugerem padronizarmos as variáveis, dado que o método é bastante sensível às

\footnotetext{
${ }^{7}$ A partir de uma série de simulações utilizando os diferentes algoritmos disponíveis no software Stata (krandom, firstk, lastk, random, prandomi, everythk, segments), optou-se pelo critério firstk, o qual define a k primeiras observações como ponto de partida para a partição dos grupos. Os clusters resultantes foram os mesmo obtidos através do lastk e também do random. Além disso, a medida Euclidiana ao quadrado (L2squared) foi utilizada como critério de minimização das distâncias das observações até o centroide dos $k$ grupos definidos.
} 
variações de natureza e magnitude ${ }^{8}$. As variáveis utilizadas para compor a análise de cluster foram escolhidas de modo a captar quatro dimensões relacionadas aos processos de aprendizado que ocorrem nas infraestruturas, conforme o quadro a seguir:

\section{Quadro 1: Variáveis utilizadas na análise de cluster}

\begin{tabular}{ll}
\hline Dimensão & Variáveis \\
\hline Interação & Cooperação com empresas estrangeiras \\
& Cooperação com empresas brasileiras \\
& Cooperação com outras instituições de pesquisa brasileiras \\
& Cooperação com outras instituições de pesquisa estrangeiras \\
& Cooperação com agências de fomento brasileiras \\
& Cooperação com agências de fomento estrangeiras \\
& Cooperação com agências de fomento governamentais \\
& Razão entre usuários externos de outras e da mesma instituição \\
& Capacidade técnica \\
& Condição das instalações físicas \\
& Condição dos equipamentos \\
& Condições de manutenção \\
& Condição dos insumos de pesquisa \\
Modernização
\end{tabular}

Fonte: Elaboração própria.

Primeiramente, são incorporadas variáveis referentes à interação das infraestruturas de C\&T com outras instituições, avaliadas quanto ao grau de importância da cooperação, podendo ser alto, médio, baixo ou não coopera. Esta dimensão se faz particularmente importante na medida em que entendemos os processos de aprendizado como sendo

\footnotetext{
${ }^{8}$ No caso das variáveis intervalares, estas foram padronizadas subtraindo-se a média e dividindo pelo desvio padrão. Já as variáveis ordinais $1_{s \ldots}, M$ foram padronizadas pela fórmula $z_{i j}={ }^{\left(r_{i j}-1\right)} /\left(M_{j}-1\right)$, onde $r_{i j}$ é o valor observado (Kaufman; Rouseeuw, 1990).
} 
interativos (interative learning). Assim, aquelas infraestruturas que atribuem maior importância à cooperação tenderiam a estabelecer mais canais para a absorção de diferentes tipos de conhecimento. Além disso, a razão entre o número de usuários de outras instituições e o número de usuários da mesma instituição nos ajuda a inferir sobre o grau de abertura das infraestruturas e como elas estrariam abertas para acolher usuários que potencialmente poderiam contribuir para a expansão da sua base de conhecimento. Trata-se de uma oportunidade rica não só em termos do que se definiu como know-what e know-why, mas também em termos de know-how e, principalmente know-who.

Uma segunda dimensão a ser considerada se refere às condições das instalações. O processo de aprendizado depende de um ambiente adequado para que ele ocorra, notadamente, no que se refere à passagem da teoria para a prática. Nesse sentido, pode-se pensar tanto em termos do avanço em processos de learning by searching ou, em alguma medida, também em termos de learning by doing, using and interacting. Para tanto, são consideradas aqui a avaliação quanto à capacidade técnica das infraestruturas (avançada e compatível em relação ao exterior, avançada para o país, mas inferior às estrangeras, ou ainda adequada e compatível com as demais infraestruturas nacionais ou, por fim, atrasadas em relação a estas), bem como as condições das instalações físicas, das condições de manutenção e dos insumos de pesquisa, podendo ser avaliadas como muito bom, bom, regular ou ruim. Por fim, é considerado também o tempo transcorrido desde o último investimento significativo em modernização.

Outra dimensão importante a ser considerada envolve a intensidade de uso das infraestruturas, expressa na frequência da realização das atividades de pesquisa, ensino, desenvolvimento de tecnologias, extensão tecnológica e prestação de serviços tecnológicos. Como discutido anteriormente, diferentes atividades exigem o domínio de diferentes tipos de conhecimento, assim como incorporam diferentes processos de aprendizado. Isto é, conforme as definições consideradas neste estudo, enquanto atividades de pesquisa e ensino estariam voltadas para processos do tipo STI, as atividades de prestação de serviços tecnológicos, extensão tecnológica e até mesmo de desenvolvimento de tecnologias carregariam consigo mais conteúdos referentes aos processos do tipo DUI.

Por fim a dimensão referente ao pessoal ocupado nas infraestruturas de C\&T é fundamental para a presente análise, uma vez que, como salientado anteriormente, o conhecimento é inerentemente individual e tácito. Assim sendo, a capacidade de gerar e absorver conhecimento para a condução de diferentes atividades e processos de inovação estariam atreladas às características dos indivíduos, como qualificação e empenho nas atividades das infraestruturas. Nesse sentido, são aqui incluídos o percentual de pesquisadores com mestrado e doutorado, assim como o percentual de pesquisadores com dedicação exclusiva (mais de 30 horas semanais), o percentual de doutores e mestres da equipe de apoio, bem como o percentual de estudantes de doutorado e também de mestrado.

Como resultado da análise, foram formados três clusters a serem avaliados em cada uma das dimensões mencionadas. O cluster 1 reúne um total de 679 infraestruturas de C\&T, o cluster 2 agrupa 485 infraestruturas, enquanto o terceiro abrange 595 delas. Enquanto os clusters 1 e 2, são constituídos majoritariamente por infraestruturas de C\&T localizadas no sudeste, o cluster 3 abrange mais infraestruturas de outras regiões. 
Figura 3: Distribuição das categorias de infraestruturas de C\&T por regiões brasileiras

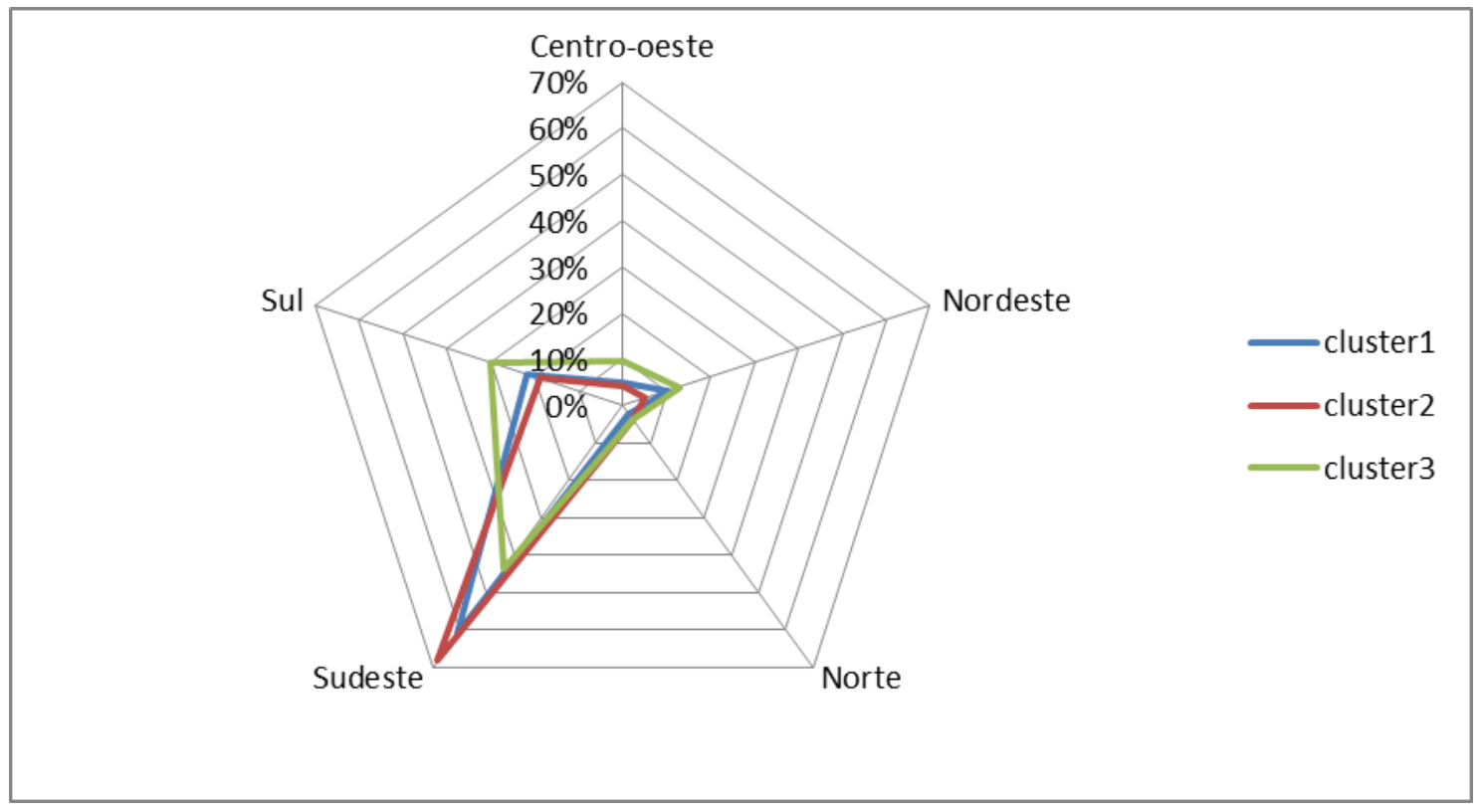

Fonte: Elaboração própria.

Enquanto os clusters 1 e 3 são compostos por infraestruturas predominantemente da área de Engenharia, o cluster 3 abrange principalmente aquelas da área de Ciências Biológicas, Ciências Exatas e da Terra, bem como de infraestruturas multidisciplinares (aquelas em que pelo menos duas áreas do conhecimento são declaradas).

Figura 4: Distribuição das grandes áreas do conhecimento

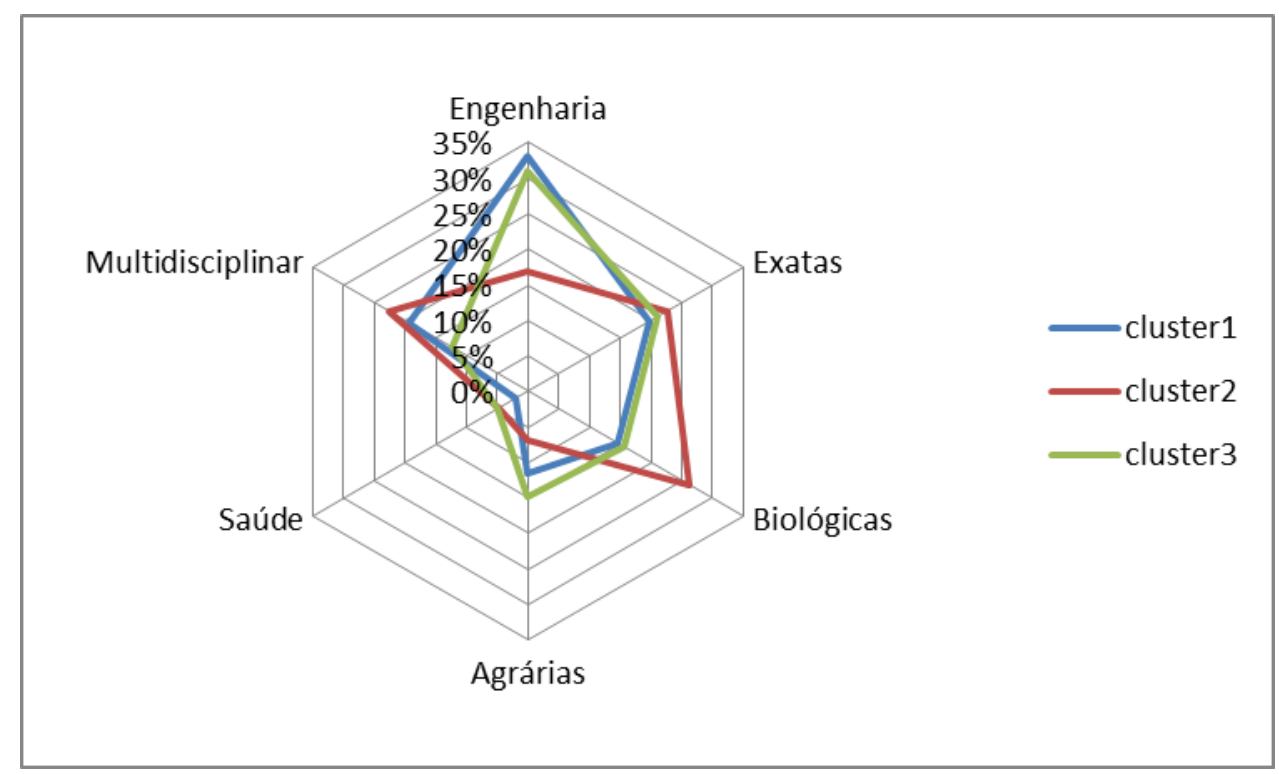

Fonte: Elaboração própria.

No que tange a importância atribuída à cooperação com outras instituições, tem-se que o cluster 3 é aquele que menos valoriza a interação e supostamente, menos se beneficiaria do processos interativos de aprendizado. Por sua vez, o cluster 2 se destaca pelo número de infraestruturas que declaram como importante a cooperação com outras instituições de pesquisa brasileiras, e em menor media as estrangeiras, além das agências de fomento 
brasileiras. As infraestruturas incluídas no cluster 1, ainda que ligeiramente em menor proporção, acompanham o cluster 2, mas se destacam pelo maior percentual de infraestruturas que valorizam a cooperação com empresas. Esse tipo de interação se faz especialmente interessante, por aproximar as infraestruturas de processos de aprendizados característicos daquilo que é definido como o modo DUI. Isso colaboraria para que as infraestruturas pudessem explorar e desenvolver conhecimentos do tipo know-how e know-who, mais característicos das empresas.

Figura 5: Percentual de infraestruturas que atribuem grau importante à cooperação

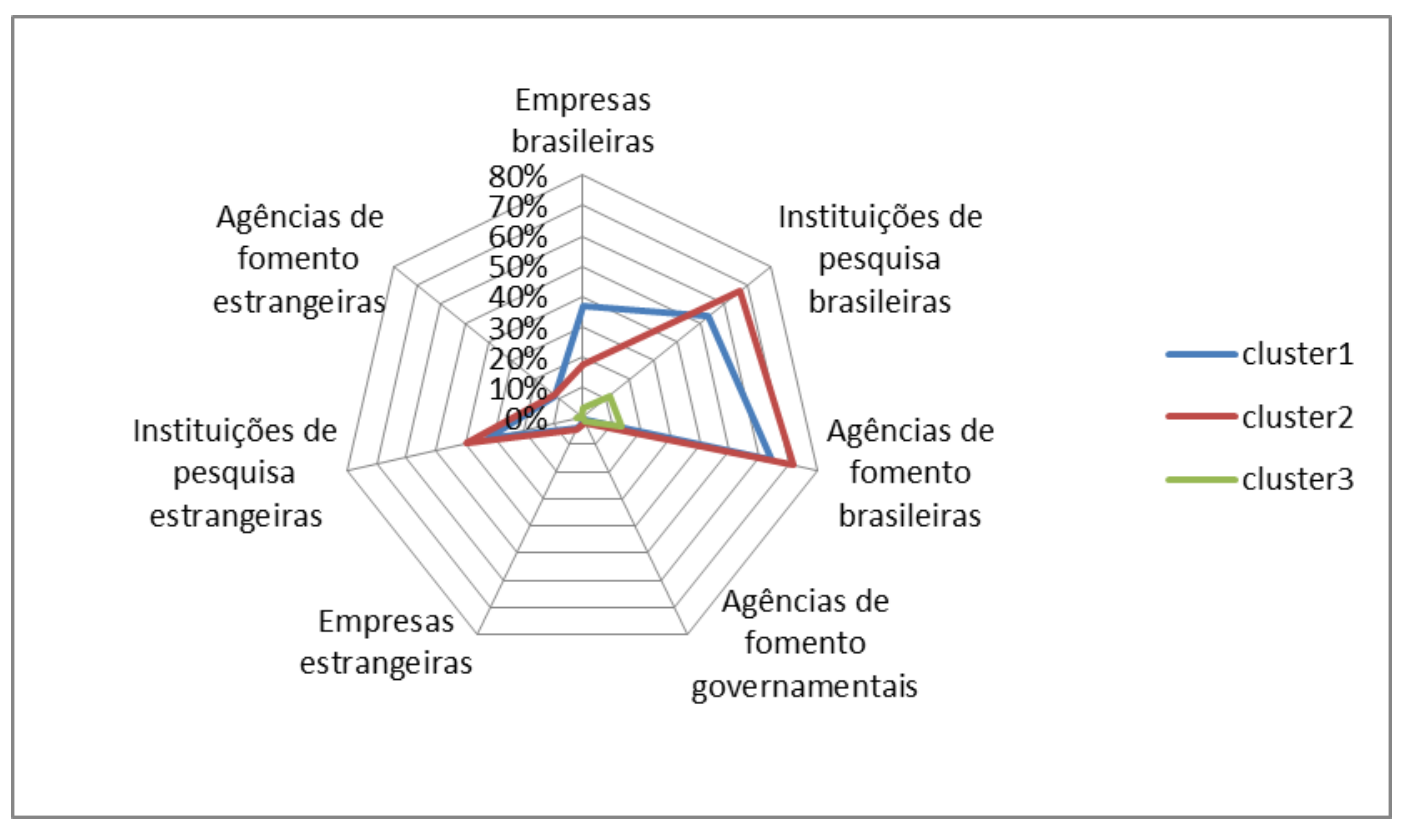

Fonte: Elaboração própria.

Por sua vez, as categorias construídas a partir da análise de cluster se diferem relativamente pouco em termos das condições das suas instalações. Observando a figura 7, percebe-se que o cluster 3 abrange menos infraestruturas consideradas avançadas para os padrões brasileiros e avaliadas como boas em termos dos seus insumos, equipamentos, manutenção e instalações. Para as três categorias, o maior problema parece ser as condições das instalações físicas, enquanto que elas se encontram relativamente mais bem atendidas em termos de manutenção. Quanto à modernização das infraestruturas, tem-se que as três categorias tiveram investimentos significativos nos últimos cinco anos, ainda que no caso do cluster 3, o número de infraestruturas tenha sido sensivelmente menor. 
Figura 6: Condições das instalações das infraestruturas de C\&T (se consideradas boas e compatíveis com os padrões brasileiros)

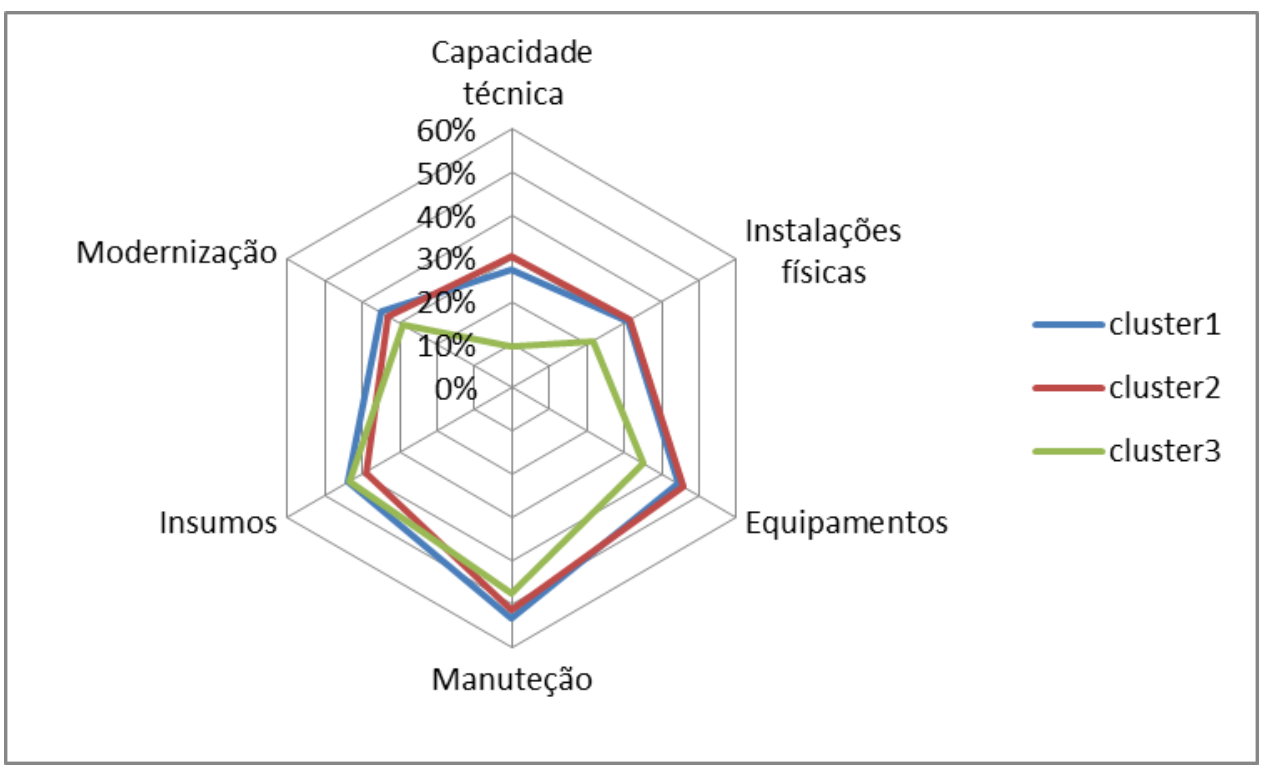

Fonte: Elaboração própria.

Um aspecto interessante que diferencia as infraestruturas de C\&T diz respeito à terceira dimensão, que contempla as atividades desempenhadas por elas. Como já havia sido verificado anteriormente, as infraestruturas são mais especializadas em pesquisa, o que envolveria fortes processos do tipo STI. Entretanto, enquanto o cluster 2 se destaca em termos de pesquisa e ensino, o cluster 1 se destaca em termos de pesquisa e desenvolvimento de tecnologias. Trata-se do cluster cujas atividades são mais diversificadas dentre os três, sendo ainda aquele com mais infraestruturas dedicadas à prestação de serviços tecnológicos e extensão tecnológica. Já o cluster 3 apresenta uma menor intensidade de utilização da infraestrutura, com uma proporção notavelmente menor de instalações dedicadas continuamente à cada uma das atividades consideradas.

Figura 7: Atividades desempenhadas pelas categorias de infraestruturas de C\&T de forma contínua

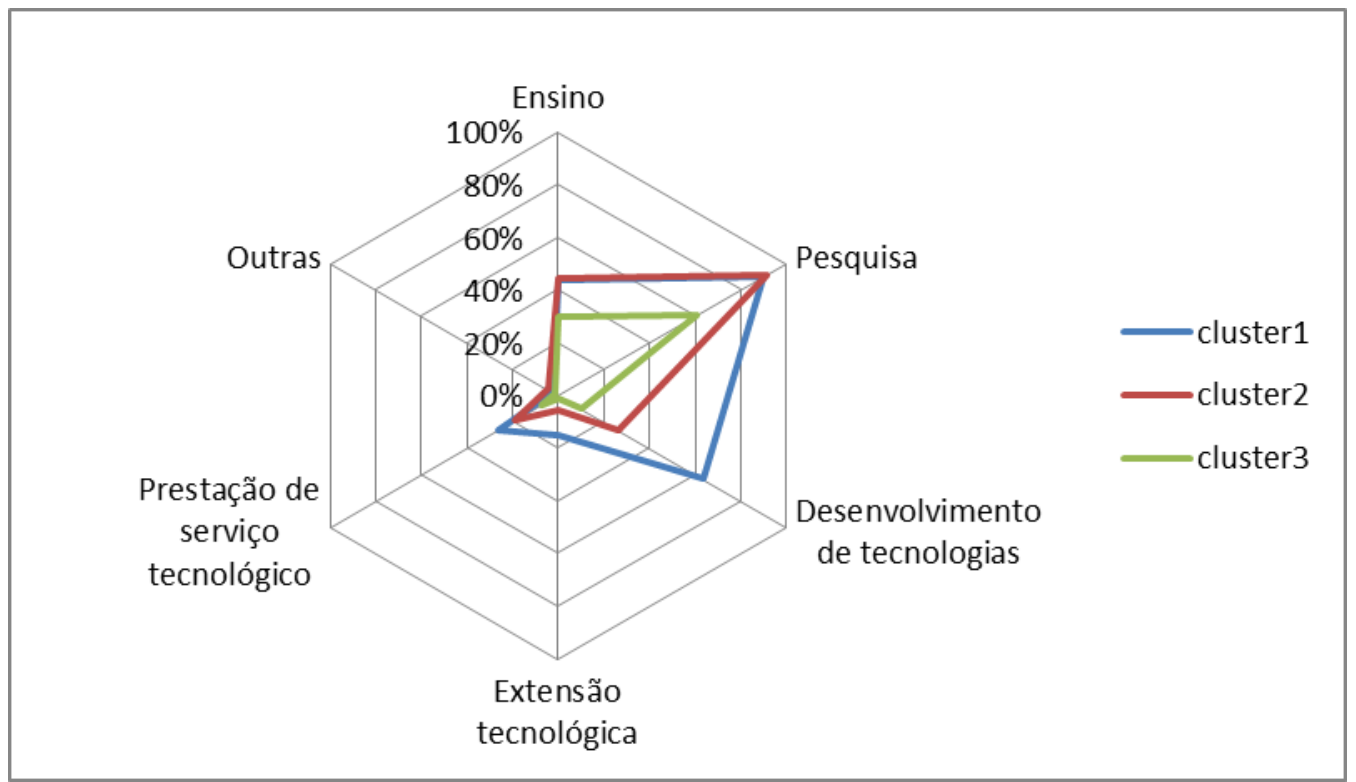

Fonte: Elaboração própria. 
Aqui se faz interessante também um olhar sobre a percepção de cada uma das categorias de clusters quanto à possibilidade de aplicação das atividades desenvolvidas na infraestrutura segundo a CNAE. Como pode ser observado no gráfico a seguir, enquanto o cluster 2 comtempla aquelas infraestruturas que se identificam majoritariamente com a pesquisa, aquelas do cluster 1 se identificam em maior proporção com a indústria de transformação. O cluster 3 mais uma vez, não ocupa uma posição de destaque e se revela como uma categoria intermediaria entre as outras duas.

Figura 8: Possíveis aplicações econômicas das atividades realizadas pelas infraestruturas

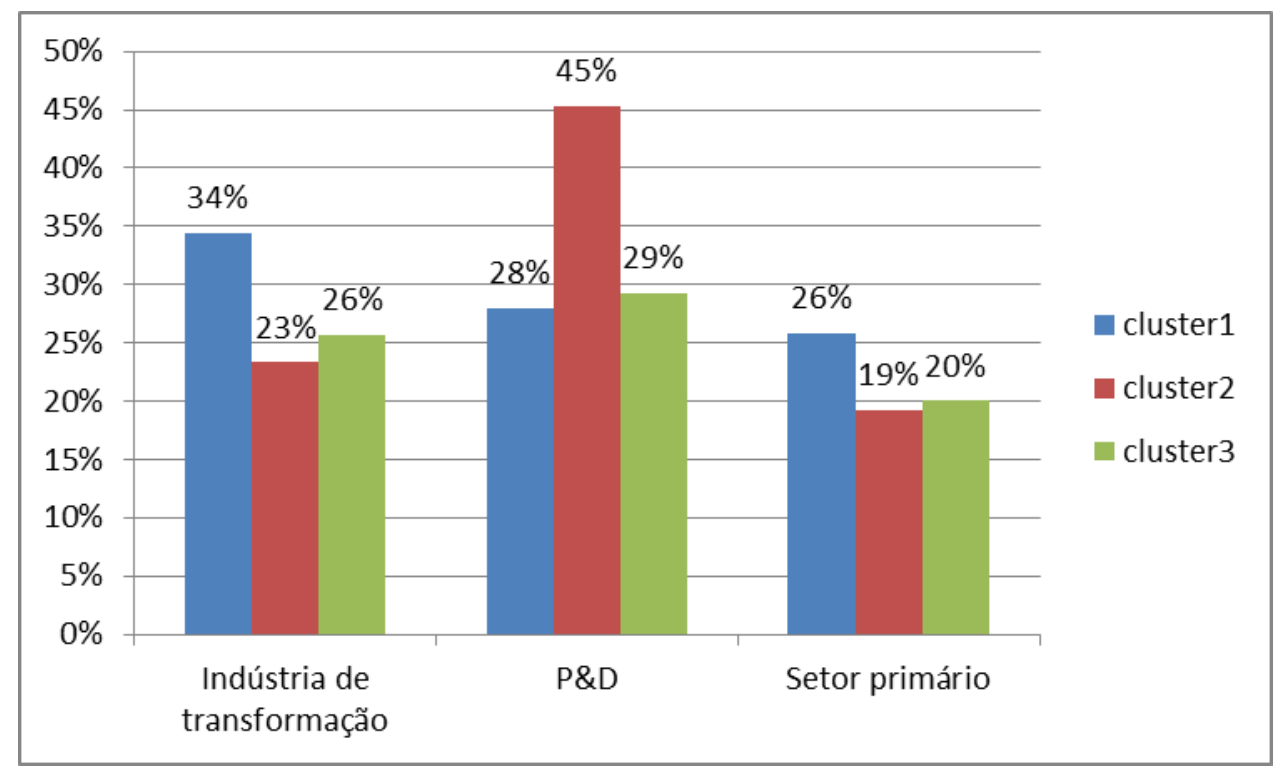

Fonte: Elaboração própria.

Quanto ao pessoal ocupado nas infraestruturas em questão, tem-se um padrão semelhante para os clusters 1 e 2. Neles a maior parte dos pesquisadores têm dedicação exclusiva e doutorado completo. A equipe de apoio não se mostra altamente qualificada e dentre os estudantes, a maior parte deles são de doutorado. O cluster 3, por sua vez, se difere principalmente pela quantidade proporcionalmente menor de pesquisadores com dedicação exclusiva e também de estudantes de mestrado e, principalmente, de doutorado. 
Figura 9: Percentual de pessoal ocupado por tipo de enquadramento

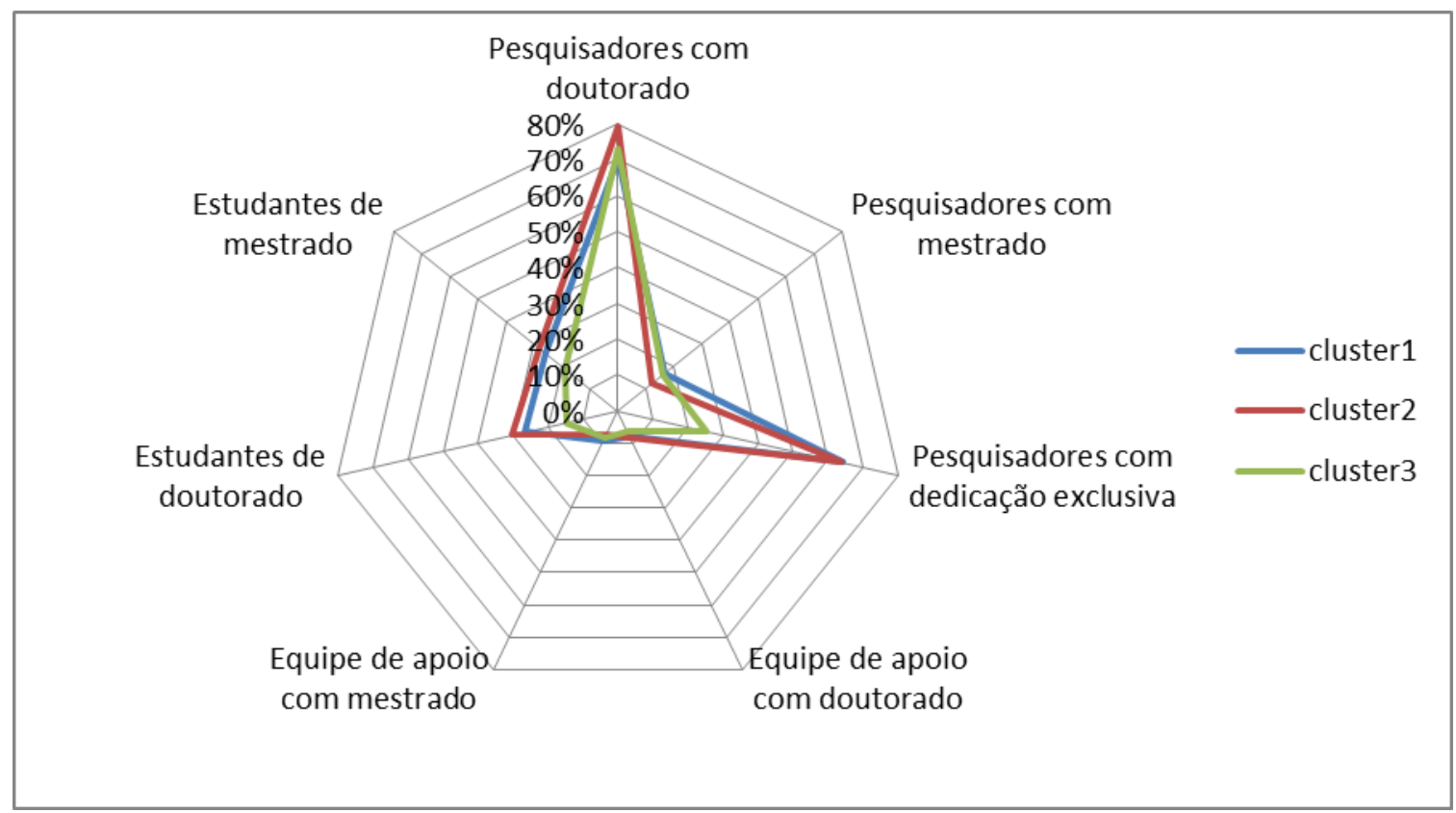

Fonte: Elaboração própria.

Com essas considerações em vista, pode-se concluir que o cluster 1 é aquele que mais tende a se beneficiar de processos de aprendizado diversos, notadamente no que tange a importância atribuída à cooperação com empresas. Ainda que enquanto infraestrutura de C\&T, predominem as atividades de pesquisa e com elas processos de STI, as infraestruturas dessa categoria parecem ter incorporado também conhecimentos oriundos do DUI. Isso se reflete na maior intensidade das atividades de desenvolvimento de tecnologias, para além da pesquisa, bem como na sua maior identificação com a indústria de transformação em relação às atividades de $\mathrm{P} \& \mathrm{D}$. Lembrando ainda que essa categoria é composta por infraestruturas localizadas majoritariamente na região Sudeste e da área de engenharia.

Por sua vez, as infraestruturas contempladas no cluster 2 apresentam características bastante semelhantes ao primeiro, notadamente no que tange suas instalações e pessoal ocupado. Entretanto, essa categoria se mostra mais intensiva em processos de STI. Isso estaria expresso na maior importância atribuída à cooperação com outras instituições de pesquisa, principalmente as brasileiras, assim como na dedicação às atividades de ensino em seguida das de pesquisa. Isso se refletiria também na sua maior identificação com aplicações possíveis em atividades de $P \& D$ em detrimentos de outras atividades econômicas produtivas da indústria, como também no setor primário. Vale por fim notar que essa categoria se refere a infraestruturas da área de Ciências Biológicas e Ciências Exatas e da Terra, ligadas à ciência pura (hard science) e menos aplicadas, como é o campo das engenharias.

Já o cluster 3 apresenta um pior desempenho em relação aos demais quanto a condição das suas instalações e a menor capacidade técnica declarada, ou ainda quanto a menor proporção de pesquisadores com dedicação exclusiva ocupados nas infraestruturas. Entretanto, chama ainda mais atenção o baixo percentual de infraestruturas que declaram como importante a cooperação com outras instituições, sejam elas empresas, instituições de pesquisa ou até mesmo agências de fomento. A atividade predominante é a pesquisa, seguida pelo ensino, embora o percentual de alunos, notadamente os de doutorado, é baixo. Importante ainda notar, que ele abrange infraestruturas em maior parte da área de Engenharia e também, com algum destaque, as da área de Ciências Agrárias. Além disso, ela abrange mais regiões brasileiras que as categorias anteriores. Entende-se, por fim, que o desempenho 
dessa categoria, poderia, de início, ser aprimorado pela maior valorização da cooperação com outros agentes. Como foi reiteradamente enfatizado até aqui, o processo de aprendizado é interativo e o acúmulo de conhecimento e capabilities para o desenvolvimento de atividades diversas depende, notadamente, dos elos que cultivem os processos interativos de aprendizado.

\section{CONCLUSÃO}

As infraestruturas de C\&T enquanto espaço dedicado à construção de conhecimento têm um papel relevante para se atingir o propósito do desenvolvimento. A definição das categorias por meio da analise de cluster é importante por revelar alguns padrões de especialização dessas instalações e confirmar algumas suposições sobre o processo de aprendizado. Primeiramente, tem-se que de modo geral se tratam de infraestruturas voltadas para processo de aprendizado do tipo STI, relacionados ao conhecimento sobre fatos e ciência, definidos em termos de know-what e know-why. Entretanto, elas podem se beneficiar dos processos de cooperação como forma de expandir sua base de conhecimento e diversificala, notadamente na interação com empresas, a partir das quais se tem contato com processos de aprendizado do tipo DUI. A possibilidade de incorporar tal forma de aprendizado relaciona-se também com a área de conhecimento da infraestrutura, confirmando a hipótese de que as áreas mais aplicadas estariam mais próximas a formas de conhecimento do tipo know-who e know-how.

A comparação do clusters 1 e 2 com o terceiro, mais incipiente, nos leva a supor que mesmo nos dois primeiros, avanços nas condições das instalações físicas e na qualificação do pessoal ocupado poderiam contribuir ainda mais para a diversificação das suas atividades e avanços nos diferentes tipos de conhecimento. Isto é, as três infraestruturas devem ainda avançar para se tornarem ambientes mais propícios à inovação e desenvolvimento de tecnologias passíveis de aplicação nas atividades econômicas. Tendo em vista que a competição é um processo dinâmico baseado em inovações, uma alternativa para que a economia construa vantagens competitivas nesse contexto seria se mover em direção às atividades mais intensivas em conhecimento. Nesse contexto, know-how e know-who se encontram no centro do processo econômico e seriam oriundos de processos de aprendizado relacionados notadamente às atividades de desenvolvimento de tecnologias.

\section{REFERÊNCIAS}

BASTOS, V.D. 2000-2010: uma década de apoio federal à inovação no Brasil. Revista do BNDES, n. 37, junho, p. 127-175.

CABRAL, R. Biotechnology, wheat production, and the Brazilian company for agricultural livestock research (EMBRAPA), 1970-1990. Science and Public Policy, v.21, n.3, p.147156, 1994.

CASSIOLATO, J. E.; GADELHA, C. G.; ALBUQUERQUE, E.; BRITTO, J. A Relação Universidade e Instituições de Pesquisa com o Setor Industrial: uma Análise de seus condicionantes, IE/UFRJ, 1996.

DAHLMAN, C. J.; FRISCHTAK, C. R. National systems supporting technical advance in industry: the brazilian experience. In: NELSON, R. (ed). National innovation systems: $a$ comparative analysis. New York, Oxford: Oxford University, 1993, p. 76-114, 1993. 
DE NEGRI, Fernanda; CAVALCANTE; Luiz Ricardo; ALVES, Patrick Franco, Universityenterprise interaction in Brazil: the role of the public research infrastructure, Discussion paper, IPEA: Brasília, 2015.

DE NEGRI, Fernanda; SQUEFF, Flávia de Holanda Schmidt. Sistemas Setoriais de Inovação e Infraestrutura de Pesquisa no Brasil. Brasília: IPEA, 2016.

JENSEN, Morten B.; JOHNSON, Björn; LORENZ, Edward; LUNDVALL, Bengt-Age. Forms of knowledge and modes of innovation. Research policy, v.36, 2007, p.680-693.

JOHNSON, Björn; LORENZ, Edward; LUNDVALL, Bengt-Age. Why all this fuss about codified and tacit knowledge?. Industrial and corporate change, v.11, n.2, 2002, p.245262.

KAUFMAN, Leonard; ROUSEEUW. Finding groups in data: an introduction to cluster analysis. New Jersey: John Wiley \& Sons Inc,. 1990.

LUNDVALL, Bengt-Age; JOHNSON, Björn. The learning economy. Journal of Industry Studies, v.1, n.2, 1994, p23-42.

METCALFE, Stanley. Innovation, competition and enterprise: foundations for economic evolution in learning economies. In: HAGE, Jerald; MEEUS, Marius (Eds). Innovation, Science and institutional change: a research handbook. Oxford: Oxford University Press, 2006).

PACHECO, C. A. As reformas da política nacional de ciência, tecnologia e inovação no Brasil (1999 - 2002). Manual de Políticas Públicas, CEPAL, Santago, setembro, 2007.

PEREIRA, N. M. Fundos setoriais: avaliação das estratégias de implementação e gestão. Texto para Discussão do IPEA, nº 1136, novembro de 2005.

SCHWARTZMAN, S. Formação da Comunidade Científica no Brasil. FINEP, 1979.

SCHWARTZMAN, S. Um espaço para a ciência: formação da comunidade científica no Brasil. Brasília: Ministério de Ciência e Tecnológia, 1991.

VELHO, L. Relações Universidade-Empresa: Desvelando Mitos. Campinas, SP: Autores Associados, Coleção educação contemporânea, 1996. 